\title{
O EMPREENDEDORISMO URBANO NA CIDADE DE BRASÍLIA: A SUBORDINAÇÃO DAS POLÍTICAS URBANAS AO MERCADO IMOBILIÁRIO
}

\author{
ROSÂNGELA VIANA \\ GILBERTO OLIVEIRA JR \\ ANANDA DE MELO MARTINS \\ Universidade de Brasília
}

\section{Introdução}

O texto ora apresentado inscreve-se no debate acerca das análises referentes à produção ampliada do espaço disposta de maneira subliminar nas políticas. A heurística ateve-se ao papel atribuído ao empreendedorismo urbano no Plano Piloto de Brasília enquanto instrumento de territorialização do setor imobiliário. As políticas urbanas desenvolvidas na cidade a partir de meados da década de 1990 articulam-se ao modelo de empreendedorismo urbano teoricamente desenvolvido por Borja; Castells (1996) e Borja (1997).

Fundamenta-se, portanto, no entendimento de que o estudo da ação de determinados grupos privados em interpenetração com a política urbana no Plano Piloto de Brasília traz importantes contribuições para as análises consoantes à (re)produção do espaço urbano. Nesta direção, o presente artigo objetiva construir uma análise do empreendedorismo urbano como prática de uma dinâmica imobiliária que, articulada à gestão urbana, subordina o espaço ao mercado (imobiliário). O processo de reprodução do espaço nos leva a indagar seu sentido em uma cidade que materialmente foi erguida no âmbito do funcionalismo da existência, contudo construída a partir de um projeto de "boas intenções" dos pressupostos da "cidade ideal".

A metodologia utilizada foi desenvolvida a partir da análise do discurso do empreendedorismo urbano, presente no Projeto Orla, enquanto intervenções urbanas de clara associação entre capital público e privado 
direcionada para a orla do Lago Paranoá em Brasília. Na análise do discurso, a concepção social na qual o texto se insere define sua materialidade e a ideologia que tangencia o enunciado. A enunciação é componente da criação da identidade, do seu processo de produção, de aproximação do poder e de constituição do corpo social pela ideologia. Por isso, esta pesquisa fundamentou-se na análise da construção teórica do empreendedorismo urbano e sua realização no processo de (re)produção do espaço na orla do Paranoá.

Em termos estruturais, o artigo se encontra dividido em 3 partes. Inicialmente elencamos os fundamentos basilares do empreendedorismo urbano em Brasília, construindo um movimento de reflexão a partir das contribuições na literatura acerca da temática. No segundo momento, nossas reflexões se detêm na análise do Projeto Orla em confronto com os argumentos teóricos construídos. Por fim, apontamos as considerações finais das reflexões desenvolvidas.

\section{O empreendedorismo urbano: primeiras aproximações}

Os discursos que tendencialmente impelem à construção do sentido da cidade em tempos hodiernos articulam a reprodução do espaço aos pressupostos teóricos do empreendedorismo urbano como conjunto de ações políticas, econômicas e técnicas para impulsionar o desenvolvimento econômico e social nas cidades. É, por isso, um modelo que continua a pressupor a racionalidade da ação capitalista e do uso da técnica, que conforma a natureza da reprodução do espaço nesse momento de desregulamentação e liberalização dos mercados pelo modelo de produtividade dado na atual mundialização.

A especificidade do empreendedorismo urbano está em administrar a cidade nos moldes de uma empresa, para assim tornar-se participante dos espaços econômicos globais. A partir daí, desenvolvem-se as condições que, no âmbito das práticas de revitalização das áreas urbanas centrais, envolvem uma nova base econômica, infra-estrutura urbana moderna, qualidade de vida, integração social e governabilidade.

De acordo com Borja, essas condições são aquelas que tornariam nossas cidades "protagonistas de nossa época" (1997, pp. 79-82). Como "marketing de cidade" (ibid., p.26) impulsionam a hierarquia no espaço urbano ao dotar determinados locais de incrementos que possam 
proporcionar um ambiente adequado ao desenvolvimento de um terciário qualificado, e, ao mesmo tempo, um determinado estilo de vida.

Esse estilo de vida adquire substância diferenciada para alguns grupos sociais que possuem condições de pagar para residir num determinado local da cidade, assim fragmenta-se o espaço e realiza-se por meio deste o fetiche da mercadoria. Dessa maneira, "uma relação social definida, estabelecida entre os homens, assume a forma fantasmagórica de uma relação entre coisas" (MARX, 2006, p. 94).

Observa-se, desse modo, o aprofundamento do discurso econômico que, no intuito de "apaziguar" a contradição histórica entre capital e trabalho, pretende dotar a administração política local em "eficácia administrativa", como salientou Compans (2005, p. 24). A eficácia administrativa como componente da construção da imagem de cidade vendável ou do city marketing, analisado por Sánchez (2003), desvela a união entre o discurso e a imagem na "construção de uma ampla adesão social a um determinado modelo de gestão e administração da cidade" (op.cit., p.25).

Entre o "receituário" proposto por Borja (1997) e a prática específica dos administradores das cidades, estão os processos que engendram a provisão diferenciada de serviços e equipamentos públicos. Essa fragmentação cria valorações distintas no espaço urbano, baseadas nos padrões de consumo (HARVEY, 2005 [1989]).

Entretanto, as fragmentações do espaço urbano não podem mais ser lidas apenas como venda de parcelas do espaço, mas analisadas como uma reorganização que garanta o consumo e realimente a acumulação capitalista em um menor tempo possível, tendo o espaço como mercadoria. Nesses termos, a (re)produção do espaço passa a se dar em consonância ao modo de acumulação atual, que implica a subordinação ainda maior dos homens e das cidades aos movimentos do mercado mundial.

Essa subordinação é analisada nas práticas das políticas urbanas em Brasília para vincular-se à capacidade de responder às injunções do mercado local e mundial. Em 1995, "a cidade passa a ter a função de gerar renda, para financiar o governo em seus projetos e estabelece como estratégia a parceria com o setor privado" (PENNA, 2000, p.130). Embora esse período possa ser caracterizado por uma "política urbana social" (ibid.), essa não se desvincula dos pressupostos do empreendedorismo urbano. 
É igualmente importante salientar que, em consonância com a dinâmica da acumulação, as cidades precisam ser produzidas para se adequar aos circuitos de valorização. Por isso, verifica-se a modernização das políticas públicas, na tentativa de solucionar os problemas dados pela própria maneira de o capital se reproduzir, expressos na competitividade urbana.

Sob essa perspectiva, desenvolveu-se o "Projeto Orla", como modelo diferenciado de gestão urbana e territorial de estruturação turística de Brasília, em conformidade aos conceitos e técnicas de planejamento empresarial. Esse projeto foi proposto pelo então governo do Distrito Federal, Cristovam Buarque (1995/1998), no intuito de efetivar políticas fundiárias de desenvolvimento urbano, no sentido de promover o crescimento econômico e a ocupação da orla do Lago Paranoá.

A base do "Projeto Orla" expressa a modernização da gestão pública pelo empresariamento urbano no Plano Piloto sem desvirtuar o projeto original da criação do Plano Piloto de Brasília. Essa modernização deve-se a uma política-administrativa que impulsionou a articulação de agentes públicos e privados no sentido de criar espaços públicos qualificados, aprimorando a infra-estrutura urbana na orla do Lago Paranoá além de estabelecer valorações. Esse Projeto divide a orla em 11 polos, onde diversas atividades terciárias seriam desenvolvidas.

É preciso considerar que as determinações urbanísticas no Plano Piloto tornam a terra raridade e contribuem para a sua alta valorização, tendo como consequência a elevação nos custos da produção imobiliária. As liberações das terras ainda sob a posse do Governo do Distrito Federal (GDF) são obstáculos, sobretudo políticos, para os construtores, incorporadores e agentes do mercado imobiliário.

O Projeto Orla retirou, em tese, tais entraves nas áreas da orla ainda pertencentes ao GDF, haja vista que, na produção de objetos imobiliários, a negociação em torno do preço da terra pôde ser reduzida. Então, ao ampliar o funcionamento da Companhia Imobiliária de Brasília (TERRACAP ${ }^{1}$ ),

\footnotetext{
1 “A Companhia Imobiliária de Brasília (Terracap), criada pela Lei $n^{o} .5 .861$, de 12 de dezembro de 1972, é uma empresa pública do Governo do Distrito Federal, regida pela lei que a criou, pelo estatuto social da instituição e pela legislação aplicável às sociedades por ações. Tem por objetivo a execução, mediante remuneração, das atividades imobiliárias de interesse do Distrito Federal, compreendendo a utilização, aquisição, administração, disposição, incorporação, oneração ou alienação de bens.A
} 
articulando-a ao desenvolvimento socioeconômico do DF a partir de 1997, o governo do Distrito Federal aportou não apenas capital fundiário para as parcerias com a iniciativa privada, mas também capital fixo, ao incorporar infraestruturas e equipamentos urbanos ao valor da terra. Esse processo se deu através da promoção de licitações pela TERRACAP para a concessão de direito real de uso, nas quais essa estabelece as características gerais e os prazos de implantação dos empreendimentos para que a iniciativa privada promova os investimentos nas premissas do Projeto.

O Projeto Orla, a nosso ver, sinaliza a mudança vinculada ao empreendedorismo urbano no conteúdo da urbanização de Brasília ao criar mecanismos que fomentassem uma cidade competitiva, atrativa, funcional, moderna e com qualidade de vida, legitimasse o governo local além de dar aos agentes econômicos garantias e viabilidades.

Dessa forma, o "Projeto Orla", registrado em cartório sob a lei de n 971 de 07/12/1995, "Reserva áreas para o Plano de Ordenamento e Estruturação Turística de Brasília - Projeto Orla", mantém-se através de projetos urbanísticos, os quais foram instituídos e assegurados por lei, muito embora nas pesquisas realizadas em órgãos do governo do Distrito Federal diversos técnicos se expressem como se o "Projeto Orla" tivesse sido extinto. Contudo, as pesquisas feitas junto à TERRACAP nos permitiram entender que, como lei urbanística, o "Projeto Orla" prevalece. A compreensão do seu significado e importância para a (re)produção do espaço urbano está no movimento de suas extensões-latências.

A análise dos movimentos de extensões-latências do "Projeto" desvela os mecanismos percorridos no processo de intensificação da coletivização privada da cidade e sob quais condicionantes se dá à reprodução do espaço no Plano Piloto. Extensões-latências aqui são consideradas como par dialético, posto que traduzem movimento e excluem a sempre presente tentação do tudo ou nada (LÉFÈBVRE, 1969, p.46-47) das análises.

Quando se afirma haver rupturas separadamente das continuidades, pressupõem-se o novo, ainda órfão da história e contido no tempo sem acaso objetivo (ibid.). As extensões na aplicação do Projeto, por muitos

partir de 1997, passou a exercer a função de Agência de Desenvolvimento do Distrito Federal na operacionalização e implementação de programas e projetos de fomento e apoio ao desenvolvimento econômico e social do Distrito Federal, nos termos do Decreto $n^{o}$ 18.061/1997" (www. terracap.df.gov.br, acesso em 11/12/07). 
considerado como extinto, se encontram presentes, por exemplo, nas construções aceleradas no Setor de Hotéis e Turismo Norte (SHTN), polo 3, a partir, principalmente, do ano de 2000. Já as latências desvelam que a essência empreendedora do Projeto não se diluiu com o término do governo Cristovam, mas no descaso de seu sucessor com as áreas públicas, que, na vigência do Projeto, haviam se tornado ponto de lazer.

Nossas análises indicam que as extensões-latências constituem os momentos nos quais, para o capital imobiliário, era propício alinharem-se ou não ao Projeto. Esses momentos correlacionados aos processos de valorizações econômicas para esses empreendimentos indicam os mecanismos utilizados na territorialização dos capitais imobiliários.

Assim, os empreendedores imobiliários valeram-se da permeabilidade das políticas urbanas, presente nas parcerias públicoprivado que, na utilização argumentativa do crescimento econômico, geração de empregos e de lazer para os jovens, acabaram por incentivar investimentos privados nos quais os agentes imobiliários fazem valer seus interesses em detrimento do compromisso social. Ao fim e a cabo, o Projeto Orla suscitou para a orla do Paranoá "visibilidade" imobiliária pelo consumo do espaço "por meio de operações vinculadas ao turismo e lazer, operações imobiliárias e, finalmente operações voltadas ao consumo da cidade, estimuladas pela publicidade" (SÁNCHEZ, 2003, p.45). Aqui o discurso encontra a forma (SERPA, 2007) e permite desvelar a sua captura pelas estratégias imobiliárias na importância simbólica e econômica do Projeto.

Nesta direção, essas construções sob a fragmentação do espaço como projeto urbanístico realizado para a implantação do Projeto em nada possibilitaram o lazer para todos na orla do Paranoá e muito menos para a satisfação das necessidades sociais dos habitantes de Brasília. Pelo contrário: a operação de revitalização da orla nesse polo permitiu a valorização imobiliária e um processo de especulação imobiliária a partir da exploração mercantil do lazer privatizado e levado a cabo nos serviços e incrementos oferecidos pelos hotéis, no período de latência.

Essa latência caracteriza o período relativo ao governo Cristovam e adquire extensões quando é abandonado o regime de concessões nas negociações dos terrenos e estes passam a serem licitados para a venda. Então volta a antiga função da TERRACAP de abastecer o mercado da incorporação imobiliária e a posse da terra passa a não estar mais sob a determinação das políticas urbanas. Como propriedade privada, aqueles 
que adquirirem as unidades habitacionais pertencentes aos empreendimentos hoteleiros podem utilizar as mesmas como melhor lhe parecer, ou seja, como residência fixa ou para investimentos lucrativos.

Tal circunstância faz emergir o vínculo entre a elaboração da política urbana de Brasília e a socialização contraditória das forças produtivas e das relações de produção. Se as formas e conteúdos da urbanização são antes formas da divisão socioespacial do trabalho, o processo urbano evidencia a contradição entre as necessidades exigidas pelo modo capitalista de reprodução para a cidade - por exemplo: qualidade de vida, inovação e coesão social - e as leis de acumulação do capital.

É necessário ressaltar que as palavras qualidade de vida, inovação e coesão social, dentro de um contexto simbólico no fortalecimento da representação do espaço, em concomitância com o poder inerente ao poder local, constituíram a senha em nossa pesquisa. Pois, embora polissêmicas as palavras-chaves mantêm com a base enunciativa do empreendedorismo urbano a condição histórico-espacial, assim uma base a priori organizada cuja função consiste em produzir alardes, legitimidade para as ações e marketing. Em última instância, sobre a coesão social, inovação e qualidade de vida, as garantias são ofertadas na cidade em que ela própria está à venda.

Coesão social, inovação e qualidade de vida dizem a respeito da organização do poder que se deseja, do controle que esse procura exercer sobre o próprio empreendedorismo urbano em relação à sua materialidade e aos fatores aleatórios que o mesmo possa engendrar. Em outras palavras, o empreendedorismo urbano é "dirigido" e adaptado a partir dos interesses que se conjuram.

Cria-se uma imagem de cidade unificada e idealizada pelo consenso. $\mathrm{O}$ rompimento deste, que configura o direito à alteridade e à política, tornase desordem, incômodo, insegurança e fragiliza o tombamento de Brasília ${ }^{2}$. No limite, objetiva-se apresentar que o dissenso coloca em risco os próprios fundamentos da sociedade moderna, da sua moral e dos seus

${ }^{2}$ O Plano Piloto de Brasília foi tornado Patrimônio Cultural da Humanidade em 1997. Necessário ressaltar que a porção territorial que foi tombada refere-se a uma área dentro da qual se localizam não somente o Plano Piloto, conjunto urbanístico planejado segundo os princípios da arquitetura modernista, mas também algumas localidades contíguas a ele, como o Cruzeiro, a Candangolândia e os setores Sudoeste e Octogonal, os quais apresentam outras lógicas de organização espacial. 
"bons costumes" e, porque não dizer, de sua qualidade de vida (expressão que, muitas vezes, legitima políticas autoritárias e vinculadas às estratégias econômicas), pela base ampla da cotidianidade, tornado objeto de organização para servir de sustentáculo da modernidade.

A (re)produção do espaço tende a esta lógica de funcionalidade. A idéia de campo cego desenvolvido por Lefebvre (2004, pp. 33-50) está posto, onde a cidade e o discurso passam a ser sujeito, enquanto os moradores, o objeto na gestão coletiva da raridade espaço - "os campos cegos instalam-se na re-presentação” (op.cit, p.39) - no movimento de socialização da sociedade.

\section{O Projeto Orla nas estratégias de realização do setor imobiliário}

A consolidação da cidade de Brasília, até sua constituição como metrópole regional, deve ser entendida no contexto da dinâmica da ocupação do território do Distrito Federal e das peculiaridades desse processo. A forma urbana concreta que emerge apresenta-se como resultado não apenas do projeto inicial de Lúcio Costa, posteriormente tombado como Patrimônio Cultural da Humanidade. Resulta, também, das políticas públicas e do planejamento urbano e dos impactos que esses provocam sobre a reprodução da sociedade e do espaço. Assim, a cidade define-se tanto como um produto resultante de um processo político, social e historicamente construído no âmbito da nação brasileira quanto da história do lugar, espacializando seus conflitos, contradições e lutas sociais.

A cidade de Brasília assim constitui-se na totalidade do conjunto dos núcleos urbanos que formam o Distrito Federal: uma área central - o Plano Piloto -; cercado pelas cidades periféricas (os núcleos urbanos), atualmente denominadas Regiões Administrativas (RAs). Para avaliar os impactos sociais e territoriais gerados pelas mudanças oriundas do novo modelo tecnológico-empreendedor, é preciso compreender a sua evolução, bem como as extensões-latências ocorridas após a implantação do Projeto Orla em relação aos empreendimentos construídos. Pois esse Projeto relacionado às operações de revitalização urbana obteve uma legitimidade tanto jurídica, como social, devido ao discurso desenvolvido para apresentá-lo como solução aos problemas econômicos, políticos, ambientais e sociais da cidade. 
É esse o contexto da emergência do empreendedorismo urbano, que, pelas estratégias discursivas, possibilita a permeabilidade entre os agentes imobiliários e os agentes públicos, realizando, nesse movimento, as estratégias do capital imobiliário no Plano Piloto. Esse Projeto também significa uma nova estratégia de ação sobre a cidade no âmbito das vantagens comparativas e atraentes a investidores. As ações dessa política urbana ora se entrelaçam, ora se afastam dos interesses diversos dos diferentes agentes do capital, mantendo, contudo, a lógica de valorização do espaço como elemento de ligação entre seus movimentos.

Segundo o relatório original de Brasília, a orla do Lago Paranoá deveria ser ocupada apenas por "clubes esportivos, restaurantes, lugares de recreio, balneários e núcleos de pesca" "evitando, assim, a localização de bairros residenciais. Em síntese, o Projeto Orla, elaborado pela $\mathrm{TCI}^{4}$ Planejamento, Projeto e Consultoria Internacional Ltda e contratado pelo GDF/DETUR e EMBRATUR em 1992, no governo anterior ao de Cristovam Buarque, procurou preservar o plano concebido para o Plano Piloto.

Constituía-se no Plano Diretor para ocupação das margens do Lago Paranoá e estava incluído no plano maior de ordenação e estruturação turística de Brasília. Foi reelaborado em 1995, concebido a partir de um estudo proposto pela Companhia Imobiliária de Brasília - TERRACAP, no qual o lazer estaria aliado ao desenvolvimento de atividades econômicas na beira do Lago Paranoá 5 , constituindo-se em seu núcleo. Nesses polos, diversas atividades deveriam ser desenvolvidas, desde hospedagem a eventos culturais, incluídos aí comércio e lazer.

O Projeto Orla, composto por 11 polos, previa a ocupação da orla do Lago Paranoá por uma alameda para pedestres e uma ciclovia. Nesses

\footnotetext{
${ }^{3}$ Contudo o Setor de Mansões do Lago, quadra 7, foi instituído durante a construção da cidade.
}

${ }^{4}$ A TCI - Planejamento, Projeto e Consultoria Internacional LTDA, constituída em 1988, denomina-se hoje ALTRAN TCBR - Tecnologia e Consultoria Brasileira S.A. Trata-se de uma empresa consultora de projetos e captação de recursos internacionais e nacionais. Associada a diversas empresas européias, japonesas e norte-americanas em grandes áreas como transportes, infra-estrutura, desenvolvimento urbano, turístico e regional, meio ambiente, saneamento e recursos hídricos, energia e crédito carbono (informações acessadas no site www.tcbr.com.br, em 02/02/08).

${ }^{5}$ O Lago Paranoá foi criado em 1959 como uma moldura do Plano Piloto de Brasília e com finalidades de recreação e paisagismo. 
polos, diversas atividades como comércio, hospedagem, lazer e cultura visariam atrair investimentos para o turismo e lazer sob a forma de hotéis, marinas, shoppings, feiras, centro de convenções, instalações culturais, restaurantes e bares.

Esse Projeto ensejou o aproveitamento paisagístico, turístico e econômico da orla do Lago Paranoá em áreas pertencentes ao governo do Distrito Federal. Em cada polo, seria permitido o máximo possível de atividades complementares, possibilitando maior dinâmica e variedade na sua utilização, com o funcionamento diurno e noturno. Esperava-se reaproximar a cidade do Lago Paranoá e devolvê-lo à população, resgatando para Brasília a idéia de "cidade viva":

O projeto, sob o ponto de vista urbanístico, envolve o esforço de renovação urbana de áreas desocupadas na orla. A valorização econômica dessas áreas associada à valorização do lago, levará seguramente a uma alternativa de qualificação desses espaços aliados a oportunidades turísticas, culturais e comerciais (DISTRITO FEDERAL, 1998, p. 13).

Esses 11 polos de atividades, voltados para a "animação urbana" junto à orla do Lago Paranoá, pertencem à proposta que foi desenvolvida tendo como meta permitir que "a iniciativa privada sinta-se motivada para assumir a responsabilidade pelos principais investimentos que viabilizem sua implantação".

As licitações efetuadas pela TERRACAP no Projeto Orla visavam a atrair investimentos por meio de projetos de parcerias entre o governo e a iniciativa privada. Portanto, concebido como um projeto de parceria público-privado, percebe-se uma clara atuação das parcerias propugnadas por Borja; Forn ([1981], 1996). Os pressupostos do Projeto Orla fundamentaram-se em:

a) A iniciativa privada deve participar não apenas nas construções dos seus próprios espaços, tais como hotéis, restaurantes, shoppings etc, mas também pode participar nas construções de espaços públicos. Como exemplo, o Centro Cultural e a Praça das Artes no Polo 3.

b) Não haverá inicialmente alienação dos terrenos públicos, utilizando-se para a implantação do projeto o instituto civil de Direito Real de Uso. 
c) Os investimentos feitos pela iniciativa privada em bens públicos e infra-estrutura serão ressarcidos pelo Governo do Distrito Federal em prazos e condições a serem fixados pelos editais e contratos.

d) Na medida em que será [sic]concedido o Direito Real de Uso, dispensando [sic] assim a iniciativa privada da compra de terreno, o capital que seria imobilizado em sua compra, poderá ser utilizado na implantação da infra-estrutura e dos espaços públicos tais como sistema viário, alameda, ciclovia, etc.

e) As licitações foram constituídas de uma concorrência do tipo técnica e preço que consistirá na apresentação de uma proposta técnica e preço, conforme as normas e edital de licitação estabelecida para cada Polo. As propostas consideradas qualificadas na qualificação técnica foram posteriormente avaliadas do ponto de vista financeiro, conforme critério de julgamento definido no edital de licitação.

f) As empresas poderão concorrer na forma de consórcio ou não.

g) A vencedora da licitação de cada polo se responsabilizará pela qualidade das atividades nos polos, bem como pela manutenção e boas condições de todas as atividades públicas e privadas constantes do Polo, em conformidade com o termo de contrato assinado (DISTRITO FEDERAL, 1998, p. 33-34).

Apesar da ampla aceitação popular que o Projeto Orla fomentou, na ocasião de seu lançamento, apenas quatro polos foram registrados em cartório como projeto urbanístico. A análise dos quatros polos que atualmente encontram-se em funcionamento aponta para o movimento que privatiza o espaço público em detrimento do coletivo. Analisemos.

O polo 3 abrange o Setor de Hotéis e Turismo Norte, de acordo com o projeto urbanístico de Lúcio Costa. A parceria entre o governo local e a iniciativa privada iniciada no governo de Cristovam Buarque além de ter possibilitado aos investidores erguer seus negócios sem desembolsar capital para a compra da terra, permitiu o aprofundamento entre política e economia na urbanização das áreas ao redor do Lago.

Ao término do governo Cristovam, a iniciativa privada adquiriu a propriedade destas terras e passou a construir condomínios residenciais de alto valor agregado, mas, mantendo características de hotéis nestes empreendimentos. Configuram, dessa forma, uma adaptação às normas urbanísticas vigentes para o setor e realizam as aspirações do setor 
imobiliário, que passou a oferecer ao mercado apartamentos e também flats destinados ao turismo de alta solvência ou a moradores locais.

O polo 6, localizado no SCES, trecho 2, conjunto 32, abriga um shopping com salas de cinema, bares, restaurantes, lojas e um amplo estacionamento tanto na sua parte frontal como na parte voltada para o Lago. Indispensável dizer que a obrigatoriedade de manutenção de uma faixa da vegetação nativa não foi respeitada.

No polo 8, funciona a Academia de Tênis, a qual abriga um hotel do tipo residência - no mesmo molde daqueles encontrados no polo 3 -, restaurantes, várias salas de cinema, lanchonetes, lojas, parque aquático, salas para convenções, amplos estacionamentos e um amplo espaço para exposições. O hotel que aí está localizado denomina-se Academia de Tênis Resort. Com amplas acomodações e serviços modernos, o hotel oferece 226 apartamentos divididos em cinco padrões de acomodações diferentes, entre essas, chalés, além de oferecer as 21 quadras de tênis do clube e a paisagem do Lago Paranoá. O espaço oferece vários restaurantes com especialidades diversas da cozinha capixaba, chinesa, italiana e japonesa, além de aulas e cursos de tênis, natação e academia.

O polo 11 consiste em uma área de restaurantes, cafés e espaços para exposições que a parceria público-privado tornou espaço público privatizado como os anteriores, no qual o próprio sistema de segurança constrange e intimida a presença de pessoas de menor poder aquisitivo, impedindo, assim, o uso da orla. Nesse polo, é proibido consumir alimentos ou bebidas que não sejam provenientes dos restaurantes locais. É conhecido como "Pontão do Lago Sul".

No caso específico de Brasília, o Projeto demonstra o empresariamento da cidade e se realiza no Plano Piloto no qual o domínio da terra urbana pelo governo local é a força maior de atração que este tipo de estratagema necessita. A venda da cidade oferece a terra urbana como garantia devido ao respaldo da lei, além da não necessidade de desembolso inicial para compra da terra, já que essa se torna concessão.

Atualmente, a utilização do termo concessão de direito de uso faz parte dos contratos firmados para as áreas localizadas no Parque Tecnológico Capital Digital, para onde o atual governo do GDF espera atrair 2 mil empresas ${ }^{0}$ envolvidas em tecnologia de informação e comunicação. Tal processo acentua a centralidade do Plano Piloto na

${ }^{6}$ Jornal da Comunidade, Brasília, 19-25 de abril de 2008, p.F7. 
gestão empreendedora da cidade, especialmente relacionada à cultura, lazer, turismo e serviços modernos.

A imagem de "cidade viva" ou adjetivações semelhantes não são construídas sem objetivações. O Projeto Orla, em tese, é construído para as exigências dos investimentos modernos e as demandas necessárias à extensão do setor terciário, é sobre esses interesses específicos ligados às normas que ele se constitui. Esse é seu determinismo axial pelas abstrações que a funcionalidade das formas adquire em Brasília no consumo do espaço que se esboça, pois a sociedade e seus processos explicam as funçõ̃es e a existência das formas no espaço.

As funções das formas confundem e provocam a falsa clareza de união - onde os fragmentos estão nas funcionalidades - e de entendimento, sobre os fins. A importância do Projeto Orla reside no fato de que ele, embora conste de forma pontual da elaboração do Plano Diretor de Ordenamento Territorial do Distrito Federal - PDOT - de 1996, congregou e operalizou o receituário empreendedor (BORJA, 1997), presente também no referido PDOT, expresso como as principais propostas da SETUR para o turismo (DISTRITO FEDERAL, 2007, p.46):

. incremento do turismo místico no DF e no Entorno;

. incremento do turismo ecológico no DF e no Entorno;

. criação do turismo rural e educativo no DF e no Entorno;

- dinamização do turismo cívico e histórico, com o objetivo de divulgar a concepção arquitetônica e paisagística de Brasília como Patrimônio Cultural da Humanidade;

- revitalização do potencial turístico do Lago Paranoá com a implantação do Projeto Orla;

- fomento ao turismo de negócios, por meio de eventos nacionais e internacionais;

- criação de um grupo de ação com objetivo de fomentar a participação do empresariado nacional e internacional;

. criação de centros de treinamento de mão-de-obra especializada em turismo nos locais de recepção do turista, em conjunto com entidades de classe;

- revisão da localização da rede hoteleira no DF, criação de novas áreas e revisão de gabaritos. 
No atual Projeto de Lei Complementar do PDOT (DISTRITO FEDERAL, 2007), o conteúdo do "Projeto Orla" encontra-se desarticulado em capítulos diferenciados. Por exemplo, no capítulo II - Do zoneamento , seção I - Da macrozona urbana -, subseção I - Da zona urbana do conjunto tombado -, artigo 66, item III "consolidar a vocação de cultura, lazer, esporte e turismo do Lago Paranoá, mediante criação e promoção de espaços adequados para o cumprimento de suas funções" (p.18). Enquanto no capítulo I - Do patrimônio cultural -, artigo 11, item II "instituir instrumentos econômicos e incentivos fiscais destinados à promoção, preservação, conservação e recuperação do patrimônio cultural"; no item VI "consolidar as potencialidades do patrimônio cultural do Distrito Federal como fator de desenvolvimento econômico e social e de geração de trabalho, emprego e renda" (DISTRITO FEDERAL, 2007, p. 7).

Isso porque o Projeto Orla diz da funcionalização da terra urbana, passo a passo, num processo de controle e simulação da realidade, coincidindo com o ideal construído para Brasília - ordem, progresso, beleza... - em contraposição ao planejamento compreensivo. É um exercício objetivado de seus idealizadores em correspondência ao ordenamento territorial, portanto, volta suas ações em sentido contrário à cidade por transformá-la em empresa.

Essa direção de empresariamento na gestão local deu-se pela possibilidade de situar, nesse contexto, a atuação do setor financeiro que se realiza no Plano Piloto em concomitância ao setor imobiliário e do terciário superior (de lazer e turismo de negócios). O par dialético - extensõeslatências - permitiu trabalhar a questão do empresariamento da cidade e a articulação entre governo local e empresários.

A sua criação, na perspectiva de um programa de desenvolvimento econômico, representou, em termos institucionais, a possibilidade da TERRACAP se realizar de fato como uma empresa pública, portanto, seguindo normas do direito privado, fator que lhe permitiu agir de acordo com os princípios comerciais. Por outro lado, áreas que anteriormente eram públicas passaram para o domínio da TERRACAP. Numa melhor exemplificação, algumas áreas que se localizavam entre determinados setores como o Setor de Hotéis e Turismo Norte (SHTN) e o Setor de Clubes Esportivos Norte (SCEN), foram loteadas, ação que permitiu a unificação desses dois setores. Como resultado, esses loteamentos tornaram-se de domínio público, fato que permite erguer construções que, diferentemente de área pública, não permitem edificações, e, passaram a 
pertencer a TERRACAP, tendo o aparato legal para serem negociados e edificados.

Os loteamentos no pólo 3 reuniram os setores hoteleiro, comercial e imobiliário, pois são esses setores econômicos que detêm grande parte de seu capital imobilizado em Brasília. Daí a relação com os parâmetros do empreendedorismo urbano de modo a ampliar a participação do setor empresarial e do investimento privado na gestão local. Por isso o Projeto Orla pode ser considerado a inserção ainda mais aprofundada da propriedade pública nos negócios das empresas de construção e de incorporação privada, devido aos quatro pólos que se tornaram efetivos enquanto projeto urbanístico, assegurado por lei. Dessa maneira, significou uma adequação ao modelo do empreendedorismo e das condições políticas internas.

Ainda que o Projeto Orla não tenha atingido o modelo empreendedor praticado no Rio de Janeiro (COMPANS, 2005), pode-se afirmar que, semelhante a esta cidade, o envolvimento dos segmentos empresariais ocorreu no sentido de influenciar as decisões políticas que lhe permitissem angariar vantagens - como aquelas propiciadas pelas externalidades para o setor imobiliário -, enquanto projeto de inovação e incremento às atividades terciárias.

Evidente que o interesse do governante municipal também reside na possibilidade de aumentar suas arrecadações fiscais e, por isso, favorecer processos de valorização imobiliária e de atividades comerciais e de serviços (OFFE, 1984). Nesse sentido, as condições políticas caminham para favorecer a acumulação e não se desassociam da conjuntura nacional.

A conjuntura nacional neste período e a situação do mercado imobiliário de Brasília, em que a oferta e escassez de terras sempre estiveram articuladas à política urbana, explica, a nosso ver, o apoio e recuo dos empresários ao Projeto Orla. Embora exista ampla aceitação por parte do empresariado, haja abandono relativo do Projeto e crescimento imobiliário principalmente no polo 3 em pouco menos de dois anos, após o término do governo Cristovam, o desempenho do poder público para estimular o capital imobiliário foi decisivo.

Ainda que o governo Cristovam fosse ideologicamente alinhado com a esquerda, fator que poderia vir a intervir na reprodução do poder do grupo imobiliário na esfera política, sua política urbana, contudo, foi conciliatória. A proposta do seu governo de um sistema descentralizado de planejamento, dotando as Regiões Administrativas de maior poder político, 
seguiu de perto as orientações catalãs: "uma política de grandes cidades exige um incremento da desconcentração territorial do Estado e o estabelecimento de novas competências e funções em relação às administrações autônomas” (BORJA; FORN, [1981] 1996, p.42).

Segundo Penna (2000, p.131), o governo desenvolveu "uma estratégia fundamental para o envolvimento e a co-responsabilidade da sociedade", configurando o que Borja (1997, p.86) preconiza ser necessário para um projeto-cidade, como "projeto de comunicação e de mobilização citadino e de promoção interna e externa da urbe". Não se pode desconsiderar que a política adotada por Cristovam teve também um sentido de ampliar seu domínio e controle das terras (diante da proliferação de condomínios irregulares) e sua tentativa de impedir o aparecimento de novos condomínios (PENNA, 2000, p. 134).

No bojo do contexto de regularização de terras públicas apropriadas ilegalmente, surgiram conflitos entre o modelo estabelecido de terras públicas e as propostas de privatizações das mesmas, embora essas terras também houvessem sido ofertadas para o mercado imobiliário e subordinadas ao planejamento urbano. Significava, para os agentes imobiliários, a necessidade de criar pressões sobre o governo para aumentar a oferta de terras, como mostra o discurso proferido por Paulo Octávio, em ocasião de sua posse da presidência da ADEMI:

A questão política permeia a nossa atividade. Brasília mudou muito nos últimos anos e sua administração se tornou mais complexa. A resposta à complexidade está em que ficou mais lento o processo de tomada de decisões. Ele passou a corresponder à capacidade de pressão e contrapressão dos grupos, entidades, pessoas e partidos políticos envolvidos em cada controvérsia. (...) a cidade não tem donos, não pertence a ninguém, além de seus habitantes. Não pertence mais a seus criadores, que produziram o ato urbanístico perfeito, nem pertence a políticos ou administradores. Brasília é dos brasilienses.(...). A construção civil é, de longe, a atividade econômica mais importante do Distrito Federal. (...). Nós não dependemos de governos para o exercício de nosso trabalho. Dependemos apenas de normas definidas, definitivas, claras e estáveis. (...). No caso do Distrito Federal, os nossos objetivos são claros: 1) Participação ativa da entidade na discussão com o GDF da política habitacional a ser desenvolvida na cidade; 2) Licitação de novas áreas pela Terracap (...);3) Aberturas 
de financiamentos pelo BRB; 4) Construção da infra-estrutura prometida para as novas áreas habitacionais (...) pelo Governo do Distrito Federal; 5) Agilização na aprovação de novos projetos e na liberação dos alvarás e habite-se pelas Administrações Regionais; 6) Sensibilização por parte do Conselho Curador do FGTS da atipicidade da Capital, que necessita de linhas especiais de financiamento; 7)Conclusão das obras do metrô; 8) Implantação do projeto Orla; 9) Redefinição da ocupação do setor Noroeste; 10) Discussão aberta com o GDF da necessidade da criação do setor Noroeste (...); 11) Apoio total para a suspensão de doar lotes, que já provocou o inchaço da cidade e acarretou graves problemas urbanos e sociais (...). Nossas empresas precisam ter presente a preocupação social. (...) uma noção nítida da função social do empresário (LINHARES, 1995, pp. 32-33).

Esse discurso de posse mostra a recusa à ampliação da oferta de terra urbana à classe baixa, apoio aos ideários neoliberais, contudo sem abrir mão das normas (ou seja, do governo enquanto guardião da propriedade privada). Por outro lado, mostra também sua busca de apoio da sociedade como um todo - ao aparentar apoio ao metrô, ao Projeto Orla e às necessidades sociais das classes médias. $\mathrm{Na}$ verdade, é expressa a urbanização do DF como uma luta que se trava pela posse do poder local, isso se a relacionarmos à ocupação de cargos políticos por um número expressivo de empresários do capital imobiliário.

\section{Considerações finais}

A análise da revitalização urbana proposta para a orla do Paranoá desvela o interesse do setor imobiliário com a produção de espaço da cidade submetido aos ditames do mercado. A cidade então é assumida como um invólucro dos produtos que nela são construídos, subsumindo os interesses coletivos.

Essas relações, conflitantes devido aos interesses diversos entre o setor público, o setor privado e os cidadãos, definem a urbanização intrinsecamente articulada nas práticas de classes, na qual o espaço condiciona as interações e também as exclusões. Como produto da urbanização, as formas construídas desvelam os conteúdos e as estratégias da classe hegemônica. 
O empreendedorismo urbano não contribui apenas para manter o discurso da gestão eficiente - o qual dá legitimidade ao governo local mas também amplia e sedimenta a crença na economia como demiurgo da sociedade, uma vez que a forma e o uso são correlatos a conteúdos sociais.

Analiticamente, as tramas que envolvem a (re)produção do espaço na lógica de grupos organizados reúnem-se no discurso e separam-se no espaço social. Pelo contexto da totalidade social, esta separação foi verificada no movimento de extensões-latências do Projeto Orla. Por conseguinte, define o sentido da materialização dos empreendimentos realizados a partir da implementação do Projeto Orla.

Estas dinâmicas distintas - privada e pública - que ora estão alinhadas, ora são divergentes devem-se aos inúmeros interesses que permeiam esses setores e que nem sempre são coincidentes, devido ao processo social de produção, das próprias relações desse processo e da dependência material de todas as partes. Contudo, precisam aparentar coerência entre suas ações para assim manter o domínio legítimo do espaço urbano. Estes conflitos compõem os interstícios das políticas urbanas e são constituintes do processo de (re)produção do espaço.

Essa circunstância é definida pela cidade-urbana, proveniente de uma necessidade real dos moradores da cidade (emprego, segurança e qualidade de vida), das necessidades de acumulação capitalista (por meio das inovações) e de busca por legitimidade e capitalização do governo local no contexto estrutural no âmbito mundial da economia. A partir dela que o discurso do empreendedorismo urbano é construído. A assunção do discurso faz emergir a tríade - qualidade de vida, inovação e coesão social - que sustenta seus pressupostos teóricos na constituição da parceria público-privada. Essa parceria atua sob o "receituário" de práticas da gestão eficiente que são reproduzidas nas políticas urbanas de Brasília e nas representações do espaço.

Esta "linguagem" traz à superfície os empreendimentos colocados à venda, como um ponto de contato entre a mercadoria e os consumidores. As estratégias contidas no discurso evocam tanto as necessidades subjetivas como as práticas competitivas entre cidades, para tornar invisíveis as relações de produção e as fragmentações socioespaciais. Resulta, portanto, a estratégia do empreendedorismo urbano como uma função enunciativa, que consiste em criar um conjunto de posições subjetivas possíveis e mesmo um espaço no qual elas sejam consideradas, utilizadas e repetidas. 
Trata-se de um processo no qual a própria cidade "fala" e, nesse falar, torna a organização e os usos como necessidades reais de todos. Dessa maneira, oculta quem fala, porque a fala é o processo que produz o significado da urbanização e o significante da (re)produção do espaço.

No corpo teórico do empreendedorismo urbano, embora se admitam singularidades nos modos de sua aplicação como planejamento estratégico que legitima prioridades na participação privada da gestão dos negócios públicos (expressas na parceria público-privada), os compromissos sociais que aquele anuncia se desmoronam pelas suas próprias práticas mercadológicas. O empreendedorismo urbano nega, na prática, sua própria justificativa e por isso perpetua as contradições nas cidades. A contradição está na sua dimensão teórica e o modo prático de sua existência.

A integração territorial da cidade, ordem necessária para o desenvolvimento do capital, em tese, é conseguida pela qualidade de vida para todos. Contudo, implica uma maior redistribuição do excedente social. Observa-se que, na sua linguagem, há uma contradição não resolvida que se materializa no próprio movimento da cidade em direção à metrópole, da imposição do valor de troca sobre a reprodução dos homens. No entanto essa contradição não é aparente. Seu signo esconde o seu significante. No Plano Piloto, esse signo é seu plano urbanístico tombado como patrimônio, o qual permite realizar a significação e prática do empreendedorismo urbano.

Assim, na relação entre os meios e os fins utilizados pelo empreendedorismo urbano na composição de uma agenda estratégica, está o valor de mercado advindo das (re)qualificações no espaço que, ao legitimar determinadas parcerias entre poder público e privado, evidenciam a acumulação como fim em detrimento às necessidades sociais. Um objetivo próprio da produção que é garantir lucro privado e, ao reorganizar a divisão social do trabalho, produzir nossa existência nos interstícios das formas pelo trabalho abstrato. Pode-se afirmar que o empreendedorismo urbano é um anunciar de falsa bonança no oceano predatório capitalista a fim de "cultivar todas as qualidades do ser humano social" (MARX, apud CLEAVER 1981, p.121).

No Plano Piloto essa contradição se esboça nas premissas do Projeto Orla e das relações gerais que existem entre o Plano Piloto e Brasília no conjunto do desenvolvimento social. Da proposta de voltar "os olhos da cidade para o Lago" emerge não apenas o espaço local tornado mercadoria e constituinte do marketing urbano, mas a própria cidade como negócio. 
Devolver o acesso à orla do Paranoá à população em termos de uso é um resgate do valor cidade, enquanto fruição, entretanto não ultrapassam o sentido de metáfora. Consiste em realizar a forma em que parcelas do espaço urbano são tornadas mercadorias e, por isso, unidades de valor-deuso e valor.

Os valores metropolitanos - no sentido de demanda solvente e das exigências do mercado - selecionam o usuário e as prioridades na prática sócio-espacial. Por exemplo, a despreocupação em relação ao problema de transporte público em Brasília coloca em evidência o acesso restrito das classes populares e o conteúdo social específico do Projeto Orla. Seus mecanismos fazem valer os interesses ligados ao mercado imobiliário e o determinado expresso no empreendedorismo desenvolvido na Capital.

Nesse sentido, o movimento de aplicação do empreendedorismo urbano em Brasília e o recorte analítico que utilizamos para compreender a ocupação, revitalização e uso das áreas ao redor do Lago Paranoá constituintes da (re)produção do espaço - traz para a superfície as estratégias imobiliárias que utilizam do discurso do governo local (revitalização e inovação de determinados espaços) para superar os limites de sua atuação no Plano Piloto. Consecutivamente, torna sua estratégia (empreendedorismo urbano) o próprio enunciado do governo local.

O empreendedorismo urbano em Brasília, diluído nos determinantes do Projeto Orla, abriu caminhos para fomentar o turismo e o setor terciário moderno. Entretanto, a (re)valorização e consumo da terra urbana local engendraram a indústria imobiliária sofisticada, cujos serviços modernos complementam os empreendimentos. Como numa espécie de triangulação, sob o empreendedorismo urbano, a (re)produção do espaço se efetua entre negócios imobiliários, terciário sofisticado e práticas de políticas urbanas, dado pelo ambiente propício que a paisagem formada pelo Lago Paranoá propicia. Utilizada como identidade simbólica da escala bucólica construída por Lúcio Costa, portanto, perpetuada na constituição da metrópole.

O discurso analisado demonstra que, para além da subordinação do espaço aos ditames do mercado, o Projeto Orla buscou suprimir a política pelo consenso, uma vez que o Outro deve se adequar à razão apresentada pela gestão do governo local. Essa gestão, por sua vez, apresenta-se assenhoreada de interesses compostos por grupos e dissimula um mundo sem divisões, apenas com papéis diferentes para cada um. A naturalização 
da sociedade de mercado encontra, assim, sua completude na persuasão discursiva e pior, na exclusão do Outro.

Os movimentos de extensões-latências no Projeto Orla mostram os investimentos públicos criando valorações aos investimentos imobiliários de maneira subliminar. Ainda que seja necessário o aprofundamento nos amplos aspectos ligados ao consumo dirigido neste subespaço, o qual por sua vez torna-se também consumo do espaço, podemos delinear alguns resultados.

Reconhecidamente como principal centralidade urbana de Brasília, o Plano Piloto, possui a função primeira de produtor da mais-valia - ressaltase que a função das cidades-satélites não pode ser desprezada na nervura da urbanização de Brasília - e de representação (e mesmo de espaço fictício, constatado pelo superdimensionamento do verde e suas mediações do fetiche natureza e fetiche público) do moderno ${ }^{7}$ contido no mundo da mercadoria.

$\mathrm{O}$ mundo da mercadoria define a funcionalidade da metrópole pela verificação de que o Plano Piloto é local de trabalho para a maioria dos habitantes de Brasília. No sentido restrito de atender às necessidades da urbanização que aqui se processa tendo o mercado da construção do tecido urbano justaposto à dinâmica global do capitalismo. Dessa maneira, o significante do empreendedorismo urbano realiza esta articulação, uma vez que sua matriz é econômica e, por isso, vinculada aos mecanismos das finanças, e não às necessidades reais do humano e do coletivo, mas a uma socialização (imposição) do capital.

Nesse movimento, a clivagem social se amplia no plano do consumptivo da urbanização presente. Advinda do plano urbanístico de Lúcio Costa, a urbanização engendrou a escassez de terrenos no Plano Piloto.

Por essa raridade de espaço - explorada ao limite pelo capital e, por conseguinte pelas políticas públicas no Plano Piloto - a (re)produção do espaço encontra seu ponto de tensão no Projeto Orla. Como consequência, a cidade adquire um significado cada vez mais destituído do urbano enquanto possibilidade de superação da funcionalização da existência - e do seu sentido coletivo. No entanto, a análise do circuito imobiliário como setor principal no processo de reprodução capitalista no Plano Piloto

\footnotetext{
${ }^{7}$ As contradições que ameaçam a Modernidade, dotam essa de um "esforço impotente pela estrutura e pela coerência" (LEFEBVRE, 1969,p. 219).
} 
desvela as contradições do espaço capitalista, debalde o predomínio de uma classe e de como esse capital crescente leva à destituição do sentido do urbano para muitos. Até mesmo o urbano é redefinido em função de valores de troca e transformado em privilégio pela sanção política do governo local no processo de mercantilização dos lugares.

\section{O EMPREENDEDORISMO URBANO NA CIDADE DE BRASÍLIA: A SUBORDINAÇÃO DAS POLÍTICAS URBANAS AO MERCADO IMOBILIÁRIO}

Resumo: $\mathrm{O}$ artigo inscreve-se no debate sobre as análises referentes à produção ampliada do espaço disposta de maneira subordinada nas políticas urbanas ao mercado imobiliário. O objetivo é analisar o empreendedorismo urbano como prática de uma dinâmica imobiliária que articulada à gestão urbana subordina o espaço ao mercado imobiliário. A metodologia foi desenvolvida a partir da análise do discurso do empreendedorismo urbano, presente no Projeto Orla, enquanto intervenções urbanas de associação entre capital público e privado direcionada para a orla do Lago Paranoá em Brasília.

Palavras-chaves: Empreendedorismo urbano, Política urbana, Projeto Orla.

THE URBAN ENTREPRENEURSHIP IN THE CITY OF BRASÍLIA: THE SUBORDINATION OF THE URBAN POLICIES TO THE REAL ESTATE MARKET

Abstract: This article registers itself in the debate about the analysis regarding the amplified production of the space disposed in a subliminal way in the urban policies, aiming at analyzing the urban entrepreneurship as practice of a real state dynamic that articulated to the urban management subordinates the space to the market. The methodology was developed from the analysis of the speech of the urban entrepreneurship present in the Orla Project as urban interventions of association between public and private funds aimed to the border of Paranoá Lake in Brasília.

Key-words: Urban entrepreneurship, Urban policies, Orla Project. 


\section{BIBLIOGRAFIA}

BORJA, Jordi.(1997) As cidades e o planejamento estratégico: uma reflexão européia e latino-americana. In: FISCHER, Tânia (Org.). Cidades estratégicas. FGV. Rio de Janeiro.

BORJA, J.; CASTELLS, Manuel.(1996) As cidades como atores políticos. Novos Estudos - CEBRAP, São Paulo, n.45.

BORJA, Jordi; FORN de Manuel.(1981) Políticas da Europa e dos Estados para as cidades. Espaço \& Debates, São Paulo, Ano XVI.

CLEAVER, Harry.(1981) Leitura política de O Capital. Zahar Editores. Rio de Janeiro..

COMPANS, Rose.(2005) Empreendedorismo urbano: entre o discurso e a prática. Editora UNESP, São Paulo.

DISTRITO FEDERAL .(1998) Relatório de Atividades: Projeto Orla Agosto de 1995 a Dezembro de 1998. Distrito Federal

. (2007) Secretaria de Desenvolvimento Urbano e Habitação.

Projeto de Lei Complementar da revisão do Plano Diretor de Ordenamento Territorial do Distrito Federal. (Proposta preliminar. Brasília: Terceira Audiência Pública).

HARVEY, David.(2005) A produção capitalista do espaço. Anablume. São Paulo.

LEFÈBVRE, Henri.(1969) Introdução à modernidade. Paz e Terra. Rio de Janeiro.

.(2004) A revolução urbana. 2.ed. UFMG. Belo Horizonte.

LINHARES, Walter. (1995) Documento ao governador. Revista ADEMI/BRASÍLIA, n. 27, nov., 1995.

MARX, KARL.(2006) O Capital: crítica da economia política. Vol. 1. 24 ed. Civilização Brasileira. Rio de Janeiro.

OFFE, C.(1984) Problemas estruturais do Estado capitalista. Tempo Brasileiro. Rio de Janeiro

PENNA, Nelba Azevedo.(2000) Brasília: do espaço concebido ao espaço produzido - a dinâmica de uma metrópole planejada. (Tese de 
doutoramento, Departamento de Geografia, Universidade de São Paulo). São Paulo.

SÁNCHEZ, Fernanda. (2003). A reinvenção das cidades para um mercado mundial. Argos, Chapecó.

SERPA, Ângelo. (2007) O espaço público na cidade contemporânea. Contexto. São Paulo. 